\title{
Estética contemporânea da periferia no documentário nacional: estudo sobre $O$ Rap do Pequeno Príncipe contra as Almas Sebosas
}

\section{A suburban contemporaneous esthetic in the national documentary: A study of 0 rap do pequeno Príncipe contra as almas sebosas}

\section{FÁBIO ROCHA}

Mestre em Comunicação no Programa de Pós-Graduação em Comunicação da Universidade Federal de Pernambuco.

E-mail: fabiorochasilva@gmail.com

Resumo

O ensaio nota em $O$ Rap do Pequeno Príncipe contra as Almas Sebosas (Paulo Caldas e Marcelo Luna, 2000) a formação de uma estética baseada no cruzamento da violência urbana com a produção artística das subculturas periféricas. A hipótese é que o filme utiliza a cadência do hip hop para propor uma ficção realista, encaixandose nas dimensões do pós-moderno.

Palavras-chave: Estéica, Hip-Hop, Pós Modernismo, Periferia, Filme Documentário.

Um filme, dupla exploração

Os personagens são ao mesmo tempo radicalmente opostos e absolutamente semelhantes. Inimigos iguais, que se perseguem e se espelham mutuamente dentro de uma realidade social onde predominam a miséria e a quase absoluta falta de perspectivas. Nesse universo, o documentário Rap do Pequeno Príncipe contra as Almas Sebosas ${ }^{1}$ é um campo fértil para refletir sobre o fenômeno da violência, a partir da revelação permanente dessa dupla face dos subúrbios brasileiros: de um lado, os elementos típicos do movimento hip hop, na forma da luta pelo reconhecimento da cultura negra e na perspectiva utópica da inclusão social de seus personagens através da poesia urbana; de outro lado, a constituição de um projeto estético que parte da violência tipificada pelos programas de rádio popular, passa pela representação simbólica do assassinato com tiros para o ar, e finalmente viaja dentro de um carro forte, insinuando uma idéia bipolar sobre as periferias das grandes cidades brasileiras.

$\mathrm{O}$ enredo do filme pode ser descrito de forma simples: trata-se da história de dois amigos que nasceram no mesmo abandono do subúrbio (especificamente os bairros mais pobres do município de Camaragibe, na Região Metropolitana do Recife) e trilharam vidas avessas com relação à violência e à busca pela inclusão e transformação sociais: Alexandre Garnizé, baterista da banda de hiphop Faces do Subúrbio, é apresentado no filme como aquele que transformou sua raiva em música; já Helinho, "justiceiro", surge como aquele que cai na espiral da violência da periferia, agindo como matador de criminosos (as "almas sebosas") em Camaragibe. 
A elaboração de uma possível estética do protesto

Além de ritmo, poesia e uma contundente história, o documentário evidencia um novo cenário. $\mathrm{Na}$ verdade, trata-se de um cenário que se constitui ao mesmo tempo de uma paisagem (a periferia, seus espaços degradados, o caos urbano) e de um contexto de relações mútuas e configurações discursivas que, de alguma forma, podem ser consideradas "típicas" da época atual. O personagem Garnizé cumpre no filme o papel de arauto. Só pode ser compreendido na sua real dimensão fílmica se associado à crescente ampliação da literatura e da arte dita "marginal" que caracteriza a produção do final do século vinte ${ }^{2}$. De fato, Garnizé surge como representante de uma esfera da arte relativamente desconhecida, que opera como se tivesse saído dos porões da sociedade. Esse desconhecimento, aliás, não se resume às classes médias ou ricas da sociedade, mas incide de forma igualmente aguda entre os próprios moradores dos subúrbios - algo que aponta para uma marginalidade da margem - e que, nesta perspectiva, reitera as classificações usuais de "arte não-culta" ou de "baixa cultura".

Garnizé, como personagem do documentário, e com seu propósito de ganhar status artístico, impregnou-se num discurso inundado por críticas abusivas, atos de censura e indefinições sociais. Como se as raízes culturais do rap e o fato de seus primeiros adeptos pertencerem às classes mais pobres da sociedade negra norte-americana, (assim como no Brasil) e, diante da evidência de um novo vetor de orgulho negro militante, sem falar de sua temática vinculada à experiência do gueto, pudesse representar uma ameaça para o status quo complacente do conjunto da sociedade. Parece possível desfazer esse agregado de mal-entendidos com a explicação de Andréas Huyssen, ao buscar separar a cultura moderna e a pós-moderna:

Uma das poucas concordâncias sobre as imagens do pósmodernismo é a respeito de sua preocupação em negociar formas de alta arte com certas formas e gêneros de culturas de massa e com a cultura da vida diária. (HUYSSEN, 1996, p.61).

Diante de $O$ Rap cabe questionar o que seria Garnizé, como personagem, se não, justamente, a representação de uma mistura de ambições proletárias e burguesas saída do subúrbio para necessariamente ecoar nos bairros nobres? O filme capta a importância desse movimento cultural periférico nos tempos atuais e começa a trilhar no universo hip hop, com suas letras que não têm escrúpulos para falar da miséria absoluta e a conseqüente violência que provoca numa espécie de retorno desagradável nas esferas da difusão cultural burguesa. Garnizé vomita o seu discurso nos mesmos canais onde circula a produção pop.

É com esse olhar contemporâneo que o filme enquadra Garnizé em sua primeira cena tocando bateria. Ouvese na trilha sonora a batida do candomblé, indicando as raízes negras que agora fazem parte das músicas da banda Faces do Subúrbio. Na cena seguinte, tendo ao fundo uma sala de aula o baterista se apresenta e dispara com o rosto bem dentro da câmera: "Sou José Alexandre Santos de Oliveira, 27 anos....", continua falando o nome da família; pai, mãe, mulher e filhos e termina dizendo: "sou baterista da banda Faces do Subúrbio, nascido e criado em Camaragibe". Isso é
2 - Cabeça de Porco éo resultado de uma parceria tripla: o rapper MV Bill, o sociólogo e ex-subsecretário de Segurança do Rio de Janeiro Luiz Eduardo Soares e o empresário do hip hop Celso Athayde. Baseado em pesquisas e experiências pessoais do trio, o livro é um mergulho no universo dos morros e periferias de nove grandes centros do Brasil. - "Can't Stop, Won't Stop - A History of the Hip Hop Generation" (não pode parar, não vai parar - uma história da geração hip hop) de Jeff Chang, 37, que há 14 anos escreve e milita no movimento.

- Hip-Hop á lápis, organizado por Toni Carlos Pereira que reúne textos de várias pessoas envolvidas no movimento.

- Movimento Hip-Hop, Educação Inclusiva, de Alexandre Takara. Neste livro ele relata a ação do movimento na periferia de Santo André em São Paulo. 
mais que uma apresentação própria, é uma identidade e referencial para todos os "manos", que como ele, usam o rap como forma de encontrar uma saída para a vida saturada de restrições nas periferias e subúrbios brasileiros, característica que daí por diante o filme irá construir. Tomando essa narrativa como ponto de partida, tenta-se entender seus códigos estéticos colocando-os como expressão da arte pós-moderna.

Nunca é demais lembrarmos que o rap é considerado um dos gêneros musicais mais relevantes da cultura suburbana contemporânea com redes de comercialização e exportação do mercado fonográfico estadunidense. É também visto como sendo mais um fenômeno social do que um evento artístico. E, mais uma vez, estamos diante de um impasse em distinguir uma arte entre cultura popular e cultura de massa.

$A$ arte popular não tem gozado de tamanha popularidade junto aos filósofos e teóricos da cultura, ao mesmo tempo, que concerne a seus momentos profissionais. Quando não é completamente ignorada, indigna até mesmo de desdém, ela é rebaixada a lixo cultural, por sua falta de gosto e de reflexão. A difamação da arte popular ou da cultura de massa (o debate sobre o termo adequado é significativo e instrutivo) parece inevitável, dada à maneira como é endossada por intelectuais de visões e atividades políticosociais radicalmente diferentes. De fato, temos aqui um desses raros casos, onde reacionários de direita e marxistas radicais se dão à mão por uma mesma causa. (SCHUSTERMAN, 1998, p.99)

Após colocar a postura dos intelectuais acima, Shusterman faz oposição a tal coalizão de pensadores e procura demonstrar a sua ao término do artigo Forma e Funk; o desafio estético da arte popular:

(...) através de uma combinação de argumentos gerais e análises concretas e detalhadas, que a arte popular não somente pode satisfazer os critérios mais importantes de nossa tradição estética, como também o poder de enriquecer e remodelar nosso conceito tradicional de estética, liberando-o de sua associação alienada a temas como privilégio de classe, inércia político social e negação ascética da vida. (SCHUSTERMAN, 1998, p.104)

Uma vez que as mudanças artísticas e as vanguardas reforçaram o dogma de que a essência da arte era a novidade, uma manifestação pós-moderna como o rap rompe com esse paradigma, quando emprega e adota de forma criativa sua apropriação de som como temática, mostrando que empréstimo e criação não são incompatíveis. Partindo daí o documentário deixa claro que o movimento rap é uma arte presente e atuante na realidade dos subúrbios brasileiros.

Com o intuito de mostrar que o movimento rap está presente em todo o país, e o mais importante: as suas reivindicações e protestos são os mesmos, o filme coloca o depoimento de um dos mais famosos rappers brasileiros, Mano Brown. Não está em Recife, não conhece Helinho nem Garnizé, muito menos Camaragibe mas, sua música e declarações mostram que a realidade das favelas do Recife não se diferencia das favelas de São Paulo. Mano Brown aparece como uma ponte que liga as intenções dos subúrbios dos extremos do país que 
vão sendo desenovelados em seus versos cantados. Esses poetas das margens defendem à distância a idéia de que o próprio saber está imerso em questões políticas e luta social. Não é à toa que Garnizé aparece dentro de uma sala de aula dando um dos seus depoimentos iniciais.

$\mathrm{Na}$ construção da estética de consciência política do rap a câmera passeia pelo corpo do baterista da banda Faces do Subúrbio onde há tatuagens de Malcolm X, Martin Luther King e Che Guevara, enquanto ele explica que tatuou as imagens devido à importância destas pessoas nas lutas sociais. Mas o que é comum em todos os rappes é a compreensão dessa manifestação como uma prática musical da pósmodernidade e como fenômeno vertical das cidades pós-industriais. As questões culturais que envolvem essas práticas são maiores e, ignorálas como protesto estético, seria ignorar também sua importância para a arte e culturas contemporâneas. $\mathrm{O}$ rap é arte popular pós-moderna que desafia não só as convenções estéticas do modernismo como estilo artístico e como ideologia, mas também a doutrina filosófica da modernidade e da diferenciação entre as esferas culturais exploradas pelo filme.

No Rap filme, o movimento rap está presente marcando a cadência e a narrativa numa clara evidência dos realizadores em abarcar todo o universo da violência, inclusive sua trilha sonora que representa toda a selvageria dos subúrbios brasileiros. Assemelhando-se em sua conjuntura ao tempo, enredo e história, típicas dos documentários ficcionalizados, ou da ficcionalização da realidade onde o fato real torna-se hiperrealista, aliando-se aí todos os elementos compatíveis com sua estética do real espelhadas nos dois personagens, Helinho e Garnizé, tão bem expressada pelo rap enquanto música.

A violência é característica do rap com suas letras que parecem grosseiras e primárias, a dicção corrompida, o ritmo duro e muitas vezes repetitivo assim como é a violência da exclusão, da miséria, da opressão e da morte matada. Pois bem, precisamos salientar o fato de que o arauto Garnizé traz na voz mais um recado para os espectadores: "Educação é a base de tudo", por isso temos a imagem de uma sala de aula com cada um dos alunos se apresentando. Uma clara intenção de evidenciar a atitude de Garnizé como símbolo de movimentos sociais e culturais nos subúrbios que podem enveredar crianças por outros caminhos que não o de detento ou presidiário. No caso de Helinho, bem que poderia ser uma criação poética de um personagem para mais uma letra de Rap, caso não fosse em si mesmo, uma inspiração da realidade que como a maioria das letras do hiphop o são. Essa parte do texto representa o esforço de entender o filme não como modelo de resistência ou dominância cultural, mas de valorizá-lo como expressão que nos seus aspectos ideológicos e estéticos se oferecem como fragmentos de seu tempo.

\section{As imagens não mentem, evidenciam}

Há quem defenda que no Rap do Pequeno Príncipe Contra as Almas Sebosas ${ }^{3}$ há uma complacência desnecessária com a violência, trazida às telas numa linguagem pop, ficcionalizando a realidade, justamente para atrair grandes públicos e servir como mero entretenimento. É bem verdade que muito da vida cotidiana recebe um tratamento estetizado e seus problemas adquirem um caráter
${ }^{3} 0$ termo Alma Sebosa foi popularizado em Pernambuco através dos programas policiais transmitidos por rádios e se tornou o bordão do apresentador de programas para a TV Cardinort. 
ficcional. Diga-se de passagem, que no filme ocorre até a representação de disparo de tiro de revólver para o ar com o claro intuito de deixar o real hiper-real. Este é outro lado do filme, que em vários momentos mergulha no universo da ficção e deixa a imaginação correr solta, que vamos buscar interrogá-lo agora.

O filme não perde a estética do rap, da periferia, da pobreza e embarca de passageiro em uma lotação pelo centro da cidade com a trilha sonora da rádio da Kombi bem audível: "A vida como ela é. Cardinor, o homem da verdade", diz o locutor. A partir daí temos imagens bem enquadradas do subúrbio em planos fixos com um rádio sempre a vista, sobrepostas pela voz do locutor policial sensacionalista. Uma indicação de que este veículo, o rádio, e em especial os programas policiais, são presenças marcantes no cotidiano da classe pobre, expressa pelo movimento hip hop. $\mathrm{O}$ sensacionalismo dos programas policiais de rádio, em particular a violência é "adotada" como expressão da periferia quando se refere a seu personagem Helinho, o Pequeno Príncipe. Ele que 'limpa' a cidade dos vândalos-assaltantesbaderneiros. A tônica está em pleno consenso com os elementos e expressões da pós-modernidade.

Na era pós-moderna, a fusão do econômico com o cultural resulta na 'estetização da vida cotidiana'. A arte pós-moderna tende a ser reflexiva, irônica. Pode-se falar, dentro desse contexto, de 'reflexividade pósmoderna' da televisão comercial, que é, em geral, reflexiva e auto-referencial, porém cuja reflexividade é quando muito politicamente ambígua. (...) Muitos dos procedimentos distanciadores, caracterizados como reflexivos, nos filmes de Godard, tipificam, agora muitos programas de televisão: a designação do aparato, (câmeras, monitores, interruptores), a ruptura do fluxo narrativo (via comerciais), a justaposição de gêneros e discursos heterogêneos - a mistura de modelos documentais e ficcionais. (STAM, 2005, p.218-219)

A referência a outro veículo de comunicação dentro do filme aparece mais uma vez quando a mãe de Helinho, sentada na sala de sua casa, assiste através de uma televisão ao filho falar sobre seu primeiro assassinato, uma estetização do cotidiano que vai seguir durante todo o filme. Uma auto-referencialidade que já virou lugar comum, e que quase sempre passa despercebida e esvaziada de sua função informativa.

E não pára por aí, as imagens de um carro de som que circulara por Camaragibe anunciando o resultado de um abaixo-assinado da comunidade local pedindo a liberdade de Helinho (ele que fazia uma "limpeza" na cidade eliminando os bandidos) nos conduzem seguidamente à estetização da periferia numa nítida intencionalidade de colocar, no início do filme, Helinho como um herói daquela comunidade. E assim, a violência recebe o mesmo tratamento dispensado pelas estações de rádio, redes de TV e jornais sensacionalistas: é estetizada e, em alguns momentos, até romantizada a narrativa da violência. O filme está em completa sintonia com a perspectiva de busca e revelação dos tempos atuais tendo como referência o mercado e se alinhando com a estética dos veículos de comunicação que buscam rentabilidade.

O ponto importante que o pósmodernismo coloca é que, virtualmente, todas as lutas políticas acontecem, em 
nossos dias, no campo de batalha simbólico dos meios de comunicação de massa. (STAM, 2005, p.221).

Uma câmera subjetiva que corre desesperadamente, nervosa, procurando uma saída pelos becos de uma favela. Tem aí uma evidência de buscar fazer ficção da realidade, uma vez que esta câmera subjetiva e perdida pelos becos e ruelas das favelas, depois de muito procurar e ficar cada vez mais apavorada com o som da sirene de carro policial se aproximando, cai por trás de um objeto e não se vê mais nada. Tudo fica escuro e a imagem seguinte é a de Helinho por trás das grades da prisão. A tensão da câmera nervosa e a pseudo fuga por entre os becos da favela acabaram na cadeia. A reconstituição está pronta e 'empacotada' para nos emocionarmos com ela. É a pura intenção de integrarse à ficção-realidade e transformarse em mais um produto de consumo.

A mais típica expressão estética do pós-modernismo não é a paródia, mas, sim, o pastiche uma paródia de mimetismo vazio e neutro -, sem nenhuma pauta satírica ou senso de alternativas, e sem nem mesmo ter, a esse respeito, qualquer mística de 'originalidade', além da irônica orquestração de estilos mortos, por isso a centralidade da 'intertextualidade' é aquilo que Jameson chama (teórico pósmoderno) de 'canibalização aleatória de todos os estilos do passado (...). (STAM, 2005, p. 219).

As imagens e a produção ficcional do real ficam claras com os organismos usados no filme para a consolidação dessa estética da periferia pós-moderna exemplificadas pelos justiceiros mascarados em cima do morro que ao final de suas falas saem um para cada lado da câmera como que indo "cuidar" de cada lado da comunidade. Junte-se a estas, as imagens que beiram o cômico disfarçado de sério do delegado Eduardo Trindade.

O que observamos é que o filme deixa prevalecer o intento de criar uma atmosfera liricizante e, para tanto, utiliza repetições de fórmulas narrativas já carregadas de fama e exauridas de tantas vezes repetidas, a exemplo da melancolia de uma mãe que chora por um filho que teme pela própria vida. Assim, enumeramos as escolhas narrativas dos diretores e as colocamos como sendo pós-modernas.

Com tudo isso, quem emite a
mensagem não pretende, de
maneira alguma, que quem a
receba a interprete como obra
de arte, nem quer que os
elementos emprestados da
vanguarda artística sejam
visíveis e fruiveis como tal. Ele
só os usa porque os julgou
funcionais. (ECO. 1998, p. $80-$
81).

Ao narrar histórias de vida tão diferentes, os documentaristas do Rap deixam claro a escolha por um produto que alcançasse mercado. Encontraram na estetização da periferia uma solução e, a seu modo, criaram mais um forte elemento da eterna dualidade romanesca: o bem contra o mal, materializada nas figuras de Garnizé e Helinho, respectivamente. Não se limitam a simplesmente sobrecarregar a trama, da forma como ela é, mas a viram pelo avesso e transformam a seqüência biográfica de ações e acontecimentos em um pretexto para reproduzirem todos os seus conhecimentos de sedução e confidência com as ânsias do espectador. Acredito que era intenção dos diretores produzirem, ludicamente, sentidos de realidade para os 
personagens que inventam ou para as pessoas reais de que se apropriaram.

0 subúrbio e apenas duas saídas

A dicotomia que primeiro nos salta aos olhos em o Rap é a de que o sujeito da periferia ou escapa pelo fazer artístico ou debanda para a violência. Recaindo sobre a favela e a maioria dos seus membros suburbanos o estigma de uma impossibilidade de saída ou transposição daquele ambiente difícil de se viver, destinado à convivência com toda forma de crime, brutalidade e fatores ligados ao tráfico. Garnizé, o "personagem do bem", narra que foi assaltado por um bandido, o Paulista, que logo Helinho "comeu", como nos relata Garnizé: "... Mandou o cara fazer o Pai Nosso. Aí, o cara na cabeça: pá". O que vemos logo depois é um revolver empunhado por duas mãos disparar seis vezes, uma atrás da outra. A fala de um dos personagens é realçada ao espectador por uma imagem que só gera mais tensão típica dos propósitos ficcionais. A ligação entre o bem e o mal como forma de sobrevivência na favela é mais uma vez retomada.

A favela aparece como um lugar de "encarnação" do mal, cuja saída se dá apenas como expressão do acaso, para aqueles poucos contemplados pela sorte do destino e que ainda não se deixaram corromper. Uma narrativa que se fecha em torno da violência e busca uma saída na música, no preenchimento de lacunas pela falta de ação do estado e precariedades de um sistema social que exclui economicamente grande parte de seus membros. Embora seja inegável uma qualidade técnica e estilística do filme, jamais podemos negar seu feeling no que se refere à produção, uso dos recursos cinematográficos e intenções de mercado, ao reforçar os estigmas em torno de uma visão da pobreza e dos ambientes a ela associados. Daí, conclui-se por uma narrativa que, embora imbuída de uma crítica social, torna o debate assustador enquanto visão do real transformado em hiperreal, diante da complexidade que o tema exige.

O que percebemos é que o Rap acaba fazendo parte daquelas estatísticas de filmes que aborda a questão da pobreza com estigmas sociais. É interessante notar que, nos últimos anos, vimos um movimento que parte do cinema para a televisão no que diz respeito a essas temáticas, como nas séries televisivas Cidade dos Homens, Carandiru, Turma do Gueto e Antônia recentemente veiculadas, algumas realizadas a partir dos longas-metragens que as antecederam e outras que viraram filmes, como Antônia.

Mais uma vez, a periferia e suas manifestações assumem um traço de exotismo e sucesso de marketing com o Rap, e se ainda assim quisermos considerá-la como arte teremos que concordar com Jameson, em sua obra Espaço e Imagem, quando diz que a experiência social da visão se distingue em três etapas no século vinte. E é a última que aqui nos interessa: "(...) a arte pop dos anos sessenta, e em seguida a completa permissividade estética dos setenta, liberaram a arte do imperativo de inovar". Para completar o pensamento:

Para Compagnon e outros, o pós-modernismo tem, assim, pelo menos uma função positiva: limpar a tradição moderna de seus motivos anti ou transestéticos, purificá-la de tudo que era protopolítico ou histórico, ou mesmo coletivo, e retomar a produção artística à desinteressada atividade estética que uma certa tradição burguesa (mas não a dos próprios artistas) sempre lhe atribuiu. (JAMESON, 1994, p. 126) 
Como vemos o pós-modernismo está cada vez mais distante dos envolvimentos e resoluções sociais como bem acaba nos reafirmando Jameson:

Outros traços progressistas do pós-modernismo - seu populismo e sua democratização democratizadora, seu compromisso como ético, com plebeu e com o feminismo, seu antiautoritarismo $e$ antielitismo, seu profundo anarquismo - quer dizer, precisamente seus traços antiburgueses, todos eles, evidentemente, devem desaparecer do mapa. (JAMESON, 1994, p.126)

Mas logo em seguida, ele nos aponta uma causa que talvez justifique toda essa isenção de envolvimento com o que poderíamos chamar de compromisso social. Pois, só assim Jameson acha que os esboços de um esteticismo totalmente novo, de um retorno completo às concepções tradicionais do belo serão visíveis. $\mathrm{O}$ Rap é mais forte ao transmitir a mensagem da violência estetizada, oca de questionamentos e carregada de extremismos próprios do pósmodernismo.

\section{Abstract}

The test note in The Little Prince of Rap against Almas Sebosas (Paulo Caldas and Marcelo Luna, 2000) the formation of an aesthetic based on the intersection of urban violence with the artistic production of peripheral subcultures. The hypothesis is that the film uses the rhythm of hip hop to propose a realistic fiction, encaixando on the dimensions of the post-modern.

Keyword: esthetic, hip hop, postmodernism, pheripler, documentay mare.

\section{Referência}

DA RIN, Sílvio. Espelho Partido: tradição e transformação do documentário cinematográfico. Rio de Janeiro, ECO/UFRJ, 1995.

EAGLETON, Terry. Depois da teoria. Rio de janeiro: Civilização Brasileira, 2005.

ECO, Humberto. "A estrutura do mal gosto" in: Apocalípticos e integrados. 5 ed. São Paulo: Perspectiva, 1998.

EScosteguy, Ana Carolina. Cartografias dos Estudos Culturais: uma versão latino-americana. Belo Horizonte: Autêntica, 2001.

HALL, Stuart. Da diáspora. Belo Horizonte: UFMG, 2003

HUYSSEN, Andréas. Memórias do Modernismo. Rio de Janeiro: Editora da UFRJ, 1996.

JAMESON, Frederic. Espaço e Imagem. Teorias do pós-modernismo e outros ensaios. Rio de Janeiro: Editora da UFRJ, 1994.

MOURÃO, Maria Dora \& Labaki Amir. $O$ Cinema do Real. São Paulo: Cosac Naif, 2005.

PENAFRIA, Manuela. $O$ filme documentário - história, identidade, tecnologia. Lisboa: Ed. Cosmos, 1999.

PRYSTHON, Ângela. Cosmopolitismos periféricos. Ensaio sobre modernidade, pós-modernidade e estudos culturais na América Latina. Recife: Bagaço, 2002.

STAM, Robert. "Teoria do Cinema: a poética e a política do pós-modernismo" in: GUINSBURG, J. BARBOSA, Ana Mãe (eds). O pós-modernismo. São Paulo: Ed. Perspectiva, 2005.

SHUSTERMAN, Richard. Vivendo a Arte. O pensamento pragmatísta e a estética popular. São Paulo: ed.34, 1998.

Data do recebimento:20/09/2008

Data do aceite: 02/12/2008 